\title{
Special Organized Educational Activity as a Factor of Prophylactic And Correction of Teenager's Deviant Behavior
} ${ }^{1}$ Boranbaev Begis, ${ }^{2}$ Alliyarov Ashraf

ABSTRACT: The aim of the article to study the problems of deviant behavior of adolescents, which are formed and aggravated due to the lack of specially organized educational activities both in the family and in educational institutions; analyze different views and approaches to the essence of deviant behavior. Methods. Theoretical analysis, generalization of scientific facts, analysis of pedagogical practice, questionnaires, observation, conversation, testing, ascertaining and teaching experiments, methods of mathematical statistics. Result. Measures for preventive and correctional and educational activities of an educational organization based on the principles:value-oriented, moral-humanistic, unity of interaction between parents, different specialists and social institutions, the priority of preventive measures, prevention andcorrection of problems, differentiation of assistance depending on the level and nature of the deviating(deviant) behavior, timeliness of socio-pedagogical and psychological assistance and support. Conclusions. The considered psychological and pedagogical aspects of educational activities adolescents with deviant behavior made it possible to identify and formulate preventive measures in educational activity of adolescents who are prone to deviation of behavioral norms. Revealed list forms and methods of educational work with children and adolescents. These measures include the improvement of the psychosocial environment for the upbringing and development of children and adolescents; educational and preventive work with the participation of competent adults, educators and psychologists; education and training, taking into account the gender and age specifics of the somatic and mental development of children and adolescents.

Keywords: psychological and pedagogical aspects of educational activities, children and adolescents with deviant behavior, psychosocial environment, preventive and corrective work, educational and recreational work, remedial and rehabilitation assistance, neglect,juvenile delinquents, deviations

Article Received: 10 August 2020, Revised: 25 October 2020, Accepted: 18 November 2020

Introduction. The modern society is saturated with the problems of deviant behavior of adolescents, violation of social norms of behavior: hooliganism, aggression, violence, theft, the use of alcoholic, smoking and narcotic drugs. It's relatedwith destruction in the late 90 s of the XX centuryeducational systems at all levels of education. The problem of deviant behaviorgrows under the influence of other harmful factors of socio-economic instability: tobacco smoking, alcohol, drug addiction, neglect, and is one of the most difficultrequiring decisions and attention from parents, teachers, psychologists, psychotherapists, law enforcement agencies. Today, the current state of society in the XXI century is saturated with aggression, violence, social orphanhood, an increase in the number of children and adolescents with deviantbehavior.Psychologists (A. A. Alexandrov,S. A. Belicheva, J. L. Kolominskiy,A. V. Lichko, A. A. Rean and others) defined the essence of deviant behavior,its typology, factors, age andsex differences in the manifestation of deviations in the behavior of adolescents. As a result of the studies carried out by the above authors, the features of the motivation of deviant behavior were established,indicating typical and individual deformations in the structuremotives, goals, needs of maladaptive children and adolescents.
The aim of the article is to study the problems of deviant behavior in adolescents, to determine knowledge of the motives for committing offenses and to formulate the tasks of value-oriented education based on a humanepersonal approach, according to which one should not only punish, but encourage and educate.

Methods: theoretical analysis of research, questioning, conversation. , testing, pedagogical experiment, methods of mathematical statistics.

Results and discussion: Deviant (deviant) behavior - actions and deeds of people, social groups, contrary to social norms or accepted standards of behavior. The main factor of the deviant behavior of adolescents is neglect in the family, school, and society. The most favorable for the development of deviations in behavior is adolescence. This period is usually called a transitional period, and indeed it is when the child stops obeying parents, teachers and beginsexpress your opinion, defend your own interests, sometimes absurd, divorced from reality. At the same time, it is necessary to distinguish between positive deviation, when social foundations are formed for the sake of creation, creativity, personal and social development, and negative, when destructive and disorganizing, asocial acts are committed. For adolescents with normal behavior and adolescents prone to deviant behavior, the main landmarks are different oppositeor the norms of morality and 
spiritual and moral values generally accepted by society.

We believe that the formation of valueoriented motivation in adolescents in teaching and educational activities will serve as a prophylaxis and prevention of deviant actions. Therefore, what is the basis of education for the motive of behavior, such will be their action or reaction in the society around them.We have found that the relationship between parents and teachers with adolescent offenders is often reduced to prohibitive, authoritarian approaches and measures of influence that not only do not eliminate the causes of deviant behavior,but, on the contrary, they stimulate the development of affective behavioral reactions in adolescents, leading to illegal violations.Based on this, we assume that the idea of value-oriented education creates pedagogical conditions for the prevention and correction of deviant behavior in adolescents.Research issues on the prevention and correction of deviant behavior in adolescents are considered in fundamentalworks of the classics of pedagogical theory (B.G. Ananiev, P.P.Blonsky, L.S. Vygotsky, B.Z.Vulfov, A.S. Makarenko,A. V. Mudrik, V. A. Sukhomlinsky, V. A. Slastenin and others). At the same time, as noted in many scientific studies, the school is still the weakest link in the system of upbringing children and adolescents, due to the priority of educational tasks. The educational process with children and adolescents in general educational organizations is carried out with a low availability of specific adequate and effective technologies for the prevention and correction of deviant behavior. From teachers and psychologists, in connection withtheir lack of new methodological approaches in the educational system of schools gives rise to problems associated with the deviant behavior of students. Today, assistance to maladaptive adolescents is carried out mainly by specialists and humane educators and enthusiasts. In modern practice, in most cases, there is no regularity and consistency in the implementation of measures of prevention and correction, as well as rehabilitation of deviant adolescents.

The changes taking place in modern society, social inequality, in our opinion, today require building the process of education of the younger generations, including children and adolescents with deviant behavior, on a value-oriented basis. Theoreticalanalysis on the topic shows that the problem we are investigating originates in the works of domestic and foreign scientists A.A.Alexandrov, S. A. Belicheva, M. Weber, E. Dyurheim, Ya.L. Kolominsky, A.V. Lichko.

A number of studies in pedagogy and psychology: B.M. Hasanova, Yu.A. Kleeberg, V.G. Kondrashchenko, D.M. Mallaeva, M.M.Murtuzalieva, P.O. Omarova are devoted to the reasons for the emergence of deviant behavior in adolescents, social and psychiatric aspects, motivationalsphere, education, correction and prevention of deviant behavior, its typology, factors, gender and agedifferences in appearance, indicating typical and individual deformations in the structure of motives, goals, needs of children and adolescents. Almost all definitions are evaluative in nature of human behavior withthe point of view of the accepted norms. At the same time, the essence of deviant behavior cannot be fully illuminated without such essential features as pedagogical and psychological factors of deviant behavior. In our study, we clarified that the deviant behavior of children and adolescents is influenced by modern trends in the development and state of society, which cause deformation of individual psychological properties of the individual and are exacerbated by the absence of a specially organized system of value-oriented education. In modern pedagogy, the main attention should be paid to upbringing on values, this will allow educational organizations to carry out work on the prevention, prevention and correction of deviant behavior.

A special place in explaining the emergence and development of deviant behavior is occupied by the manifestation of adolescents' motivation, which can be formed positively in the context of value-oriented education in educational organizations. The formation of positive motivation for behavior in adolescents is one of the most important tasks of pedagogy and psychology in solvingproblems of deviant behavior. The solution to this problem in the context of upbringing on values seems to us reasonablefor the prevention and correction of deviant behavior in children and adolescents. Measures of pedagogical, psychologicaland social prevention, correction and rehabilitation of children and adolescents used by us in the study included inyourself: a set of forms, methods, means, programs, principles and rules for working with deviant adolescents, and also contained value guidelines and wereaim to provide opportunitiestheir harmonious development, education moral qualities, providing themlegal guarantees, social control,also included preventive (prophylactic) measures and psychological methods of correcting deviant behavior that had already arisen.

The regulatory and legal basis for organizing assistance to children and adolescents is the adoption of the "Convention on the Rightschild "(December 5, 1989), ratified in our country. The Convention defines a number of fundamental guidelines for family and school education, the development of measures of social and legal protection, child protection.To implement in a formative experiment the set goals and objectives in value-oriented education, we relied on the following principles that have been actively used recently in psychological and pedagogical research: 
personality-oriented, value-oriented, moral and humanistic, the principle of differentiation and individualization, complexity,correctional focus.

All work with deviant adolescents and providing them with assistance included three stages: preventive, prophylactic and correctional and rehabilitation.The main pedagogical field for their implementation was the socio-cultural environment and education on classical values. Important aspects in this matterwere prevention and prevention deviations. Preventive measures begin with the identification of minor causes of the manifestation of violations on the part of children and adolescents. We usedmethod of observing children in free activities for them and recorded all these violations in a special journal at recess, in the cafeteria, gym, on the street. In addition, we had a conversation with the parents, where it was proposedparents also record violations that children show at home and with their friends and family. To motivate parents to participate in this, we carried out explanatory work, the purpose of which was to provide them with psychological assistance in raising and accompanying their child and ensuring success in learning.

The next stage was the work on diagnostics, and then the prevention of deviant behavior, which we first of allassociated with the management of the process of socialization of children and adolescents in the family, onstreet and in an educational organization. Fromthis purpose created favorable conditions for the normal development of the child, the elimination of desocializing influences of the environment and education. We classified the most significant forms and methods of working with children andadolescents: improving the psychosocial environment for the development of the child in the family, onstreet, in an educational organization;organization of free time through additional education: classes incircles, sports sections; educational activities aimed at increasing the level of competence of interacting with children and adolescentsadults in education; ethnic, confessional and genderapproaches taking into account their somatic and mental development. Organization of specialized help for parents included: conversations, trainings on the use of techniques, installations for the prevention of violations in family communication, and teachers on the problems of personal and of a professional nature, to prevent psycho-emotional overload, teaching staff of educational organizations - to optimize the sphere of interpersonal interactions onvalue-based education.

Conclusion Modern education and implementationFederal State Educational Standards (FSES) for variouslevels are called in the learning process psychophysical overload, which has a negative impact on the somatics and the child's psyche, which requires their warning from the school management,a medical worker, a psychologist and the entire teaching staff. Therefore,we recommended carrying out social hardening of children and adolescentsin order to prepare them for stressful situations, teach them rational ways to relieve the load of psychoemotional stress in problem situations, withusing the techniques of psychotechnics and psychotechnical games [4].

A significant direction in preventive work with deviant adolescents is the coordination of common goalspedagogical influences of parents, teachers, pedagogical teams withtaking into account the peculiarities of the development of individual and personal properties of a particular adolescent as a practical implementation individual and differentiated approaches in value-based education and training.It should be noted that for prevention is essential permanent psychological and pedagogicalstudying and tracking adolescent offenders throughout the entire periodteaching at school, timely identification of the state of development and disorders. Fromfor this purpose, we organized psychological and pedagogical consultations with the aim of analyzing the behavior of schoolchildren and developing recommendations for taking preventive measures on the part of parents andteachers. Correctional and rehabilitation work in helping deviant adolescents involved special methods of correction and rehabilitation with deviations arising from the purpose of restoring them in status and legal capacity. Corrective action was mainly directed atto destroy certain non-normative attitudes, beliefs, values, stereotypes, motives of behavior, what contributed to the success in the selfrealization of the individual in the surrounding society.

Adolescent behavior is dictated by personal desires ("I want") and a desire to gain approval from reputable adults, friends, or socially significant groups. Therefore, in this age period, the most significant pedagogical conditions, as the formative experiment showed, is the environment andvalueoriented education.The study showed thatthat correctional and educational work with deviant adolescents with supportvalue-oriented education and training should be built and decided by two parties: those whoalso educates those who teach in a constantly changing and multipolar society.To solve this problem, we have developed a model of an integrated psychological and pedagogical approach to interactionin the educational process of specialistsdifferent profiles in providing adequate personality-oriented assistance to children and adolescents prone to deviant behavior. At the same time, a decisive factor that permeates all preventive, correctional, psychological and pedagogical in educational organizationswork is value-based education. 


\section{References:}

1. Bazhukova O.A Influence of modern society on the emergence of crisis situations and conditions among youth / Psychological support of adolescents and youth in difficult life and crisis circumstances: XXI century. 2017.S. 137-142

2. Vygotsky L.S Collected Works. T. 5.M. : Pedagogy, $1983.368 \mathrm{p}$.

3. Mallaev.D.M The system and continuity of psychological support for adolescents and youth in difficult life and crisis circumstances of modern society. 2017.p. 125-130.

4. Mallaev.D.M, Gasanova.D.I. Theory and practice of psychotechnical games. $2013.200 \mathrm{p}$

5. Mallaev D.M, Dibirov MI Prevention and correction of deviant behavior of adolescents in society in the context of value-oriented education. Psychological and Pedagogical Sciences. 2016. T. 10.No. 2.P. 52-57.

6. Feldstein D.I. Psychology of education of adolescents. M.: Knowledge, 1978.326p.

7. Berdimuratova, A. K., \& Mukhammadiyarova, A. J. (2020). Philosophical and methodological aspects of the interaction of natural environment and man. International
Journal of Pharmaceutical Research. https://doi.org/10.31838/ijpr/2020.12.03.235

8. Pirnazarov, N. (2020). Philosophical analysis of the issue of spirituality. International Journal of Advanced Science and Technology, 29(5).

9. Pirnazarov, N. R. uli. (2020). INFLUENCE OF VIRTUAL REALITY ON THE SPIRITUALITY OF INFORMATION SOCIETY. EurasianUnionScientists.

https://doi.org/10.31618/esu.24139335.2020.2.71.587

10. Berdimuratova

A,

«TileubergenJumamuratovshıǵarmashılıǵıfilosofiya liqanalizdiń ob'ekti retinde», Adam álemi 3 (85) 2020, 19-28

11. KurmanovAibekPuharbaevich, IbragimovBayniyazAytbaevich. Psychological-pedagogical features of studying enterprise (entrepreneurship education in the system of public education). PalArch's Journal of Archaeology of Egypt / Egyptology, 17(7), 1294712950. Retrieved from https://archives.palarch.nl/index.php/jae/article/vie w/4975 